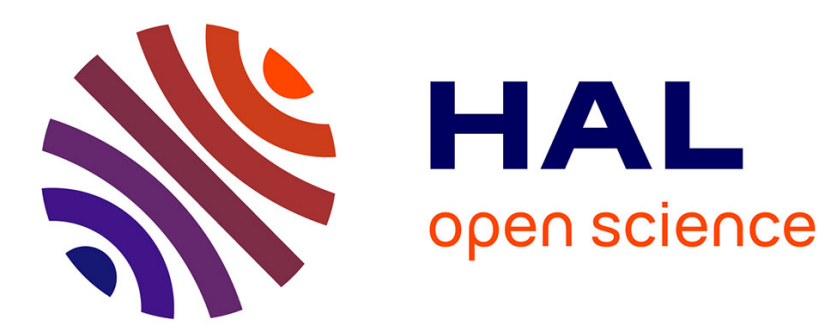

\title{
REDES POLÍTICAS INFORMALES EN LA IZQUIERDA URUGUAYA DEL SIGLO XXI
}

Florencia Dansilio, Maximiliano Duarte

\section{To cite this version:}

Florencia Dansilio, Maximiliano Duarte. REDES POLÍTICAS INFORMALES EN LA IZQUIERDA URUGUAYA DEL SIGLO XXI. Canadian Journal of Latin American and Caribbean Studies / Revue canadienne des études latino-américaines et caraïbes, 2007, 32 (63), pp.185-212. halshs-00869218

\section{HAL Id: halshs-00869218 \\ https://shs.hal.science/halshs-00869218}

Submitted on 4 Oct 2013

HAL is a multi-disciplinary open access archive for the deposit and dissemination of scientific research documents, whether they are published or not. The documents may come from teaching and research institutions in France or abroad, or from public or private research centers.
L'archive ouverte pluridisciplinaire HAL, est destinée au dépôt et à la diffusion de documents scientifiques de niveau recherche, publiés ou non, émanant des établissements d'enseignement et de recherche français ou étrangers, des laboratoires publics ou privés. 


\title{
University of Calgary Press \\ Canadian Association of Latin American and Caribbean Studies
}

\author{
REDES POLÍTICAS INFORMALES EN LA IZQUIERDA URUGUAYA DEL SIGLO XXI \\ Author(s): FLORENCIA DANSILIO and MAXIMILIANO DUARTE \\ Source: Canadian Journal of Latin American and Caribbean Studies / Revue canadienne des \\ études latino-américaines et caraïbes, Vol. 32, No. 63 (2007), pp. 185-212 \\ Published by: University of Calgary Press on behalf of Canadian Association of Latin American and \\ Caribbean Studies \\ Stable URL: http://www.jstor.org/stable/41800601 \\ Accessed: 02/10/2013 11:06
}

Your use of the JSTOR archive indicates your acceptance of the Terms \& Conditions of Use, available at

http://www.jstor.org/page/info/about/policies/terms.jsp

JSTOR is a not-for-profit service that helps scholars, researchers, and students discover, use, and build upon a wide range of content in a trusted digital archive. We use information technology and tools to increase productivity and facilitate new forms of scholarship. For more information about JSTOR, please contact support@jstor.org. 


\title{
REDES POLÍTICAS INFORMALES EN LA IZQUIERDA URUGUAYA DEL SIGLO XXI
}

\author{
FLORENCIA DANSILIO \\ MAXIMILIANO DUARTE \\ Universidad de la República Oriental del Uruguay
}

Resumen. El presente artículo pretende reflexionar sobre la existencia y vigencia de mecanismos informales de cooptación y construcción de adhesiones políticas en las elecciones municipales 2005 en Uruguay. Para esto, se propone el concepto de "mediación política" como un sustituto de lo que la literatura sobre el tema ha catalogado como "clientelismo político" a lo largo de los años. La "mediación" sugiere una forma de articulación entre diversos actores políticos y sociales, comunitarios y partidarios, que implica el contacto inter-personal de dichos actores y al mismo tiempo una circulación real o potencial de recursos. El análisis aborda como éste tipo de prácticas "híbridas", son legítimas y efectivas tanto para el éxito electoral en términos de obtención de votos como para la construcción de identificaciones políticas y sociales relativamente estables en contextos latinoamericanos.

\begin{abstract}
This article reflects upon the existence of informal mechanisms of co-optation and construction of political adhesions during the local municipal elections of 2005 in Uruguay. For this purpose the authors propose the substitution of the phrase "political mediation" for "clientelism," a traditional concept used by specialized studies. "Mediation" refers to coordination between various political and social actors that implies interpersonal contact amongst them and, at the same time, the circulation of resources (real or potential). The authors try to analyze how these "hybrid" practices of "mediation" are effective and legitimate, not only for electoral success, but also for the construction of relatively stable political and social identities in the Latin-American context.
\end{abstract}




\section{Introducción}

El presente artículo surge de una investigación realizada en el marco del taller sobre Sociología Política de la Facultad de Ciencias Sociales de la Universidad De La República Oriental Del Uruguay. Se observó la organización y el funcionamiento de redes de relaciones interpersonales tejidas en torno a una candidatura para las elecciones municipales ${ }^{1}$ en el Departamento de Canelones ${ }^{2}$ y la influencia que estas poseen en la generación de adhesiones y lealtades políticas duraderas. A partir de los resultados obtenidos en dicha investigación es que surge el interés por profundizar en la reflexión sobre los mecanismos informales de cooptación del voto y la vigencia que los mismos parecen presentar en las contiendas electorales de las localidades uruguayas.

Entendemos que el estudio del relacionamiento político "cara a cara" puede resultar un aporte fundamental a los análisis que se ocupan de los factores que intervienen en la orientación del voto: debido a que el enfoque particularista de la orientación electoral ha sido poco desarrollado en comparación con aquellos que atienden a aspectos ideológicos o comunicacionales. El auge de la tele-política o política massmediática, ha concentrado la atención de los investigadores relegando la importancia de las vinculaciones interpersonales como factores explicativos de la conformación de las adhesiones políticas. Entendemos que este tipo de influencias particularistas, dentro de las cuáles se encuentra el clientelismo, no desaparecen con el desarrollo de los medios masivos de comunicación, tampoco intentamos establecer una supremacía de unos sobre otros, simplemente señalar que los intentos de explicación de la orientación electoral pueden reforzarse con la inclusión de este tipo de aspectos.

La literatura sobre clientelismo político se ha adscrito de forma generalizada a la presentación del tema a través del corte dicotómico entre lo tradicional y lo moderno, o mediante su correlato latinoamericano; barbarie y civilización. Bajo estos preceptos se posiciona al clientelismo como el mecanismo de participación política en sociedades tradicionales, en oposición a los mecanismos de participación moderna englobados en el concepto de ciudadanía. De acuerdo a esta óptica, el clientelismo se encuentra destinado a desaparecer en la medida de que las sociedades transiten el camino unívoco de la modernización. ${ }^{3}$ Esto supone, que las mencionadas formas de partici- 
pación son incompatibles, elemento ampliamente rebatido por autores como Escalante (1995), Gay (1997), Günes-Ayata (1997), Auyero (2001), O`Donnell (1996). Como sostiene Escalante, conceptos como ciudadanía y clientelismo se pueden definir de modo que sean analíticamente opuestos, incluso contradictorios, en un caso se obedece a la ley y en otro a la influencia personal; en un caso se actúa en pro del interés público y en el otro en base a intereses particulares, por que la identidad política se define en un espacio igualitario, mientras que en el otro se establece en un orden jerárquico. Pese a esto nada los hace incompatibles en la práctica,

a menos que se suponga que la política es un campo homogéneo y que una sola y misma lógica gobierna todas las acciones. (...) De modo que si vienen a oponerse no es por un imperativo lógico sino por la necesidades de un singular modelo cultural: de hecho, la oposición y el transito que implica, resume una serie de conjeturas sobre la naturaleza de la política en la modernidad. (Escalante 1995, 32)

En los marcos democráticos dentro de los que se inscriben los gobiernos latinoamericanos, las instituciones formales conviven en constante tensión-y articulación — con instituciones informales como son las pautas de relacionamiento político informal estudiadas, y lejos de ser estas últimas mecanismos tradicionales tendientes a desaparecer, se erigen a principios del nuevo siglo como una forma factible, viable y legítima de "hacer política".

Dentro de un extendido proceso de izquierdización en Latinoamérica, vale preguntarse cómo se relaciona la Sociedad Civil con los gobernantes y cuáles son los mecanismos más efectivos de intermediación. En Uruguay el triunfo de la izquierda en las últimas elecciones nacionales de octubre del 2004 y en ocho de los diecinueve departamentos del país en las elecciones municipales de mayo del 2005 puso en discusión algunas de estas interrogantes.

La democracia fundada en una concepción individualista de la sociedad, pone a ciudadanos, iguales entre si, como los legítimos sujetos políticos, lo que supone un vínculo directo del individuo con el Estado donde prime el ejercicio del poder público en público (Bobbio 1991; O'Donnell 1996). Este funcionamiento "ideal" no tiene un correlato en la práctica, donde entre diversos motivos pretendemos 
establecer dos: en primer lugar, por mas fragmentada que se encuentra la sociedad, la acción social se encuentra enmarcada y orientada por diversas "configuraciones especificas"-comunidades, corporaciones, asociaciones, redes, etc. - que poseen jerarquías, recursos, criterios de inclusión y exclusión, que son manejados con relativos grados de autonomía (Escalante 1995). En segundo lugar, la relación entre Estado y Sociedad no se establece de forma directa, sino que se encuentra mediada por grupos de políticos profesionales, organizados en partidos políticos, que pugnan por el control estatal.

En el presente estudio se pretende analizar una forma específica de intermediación entre los Partidos Políticos y la Sociedad Civil observada en la campaña municipal de la fuerza política de izquierda uruguaya: la mediación política a través de la construcción de "referentes locales". Estos referentes surgen como interlocutores locales válidos que establecen formas informales y legítimas de relacionamiento de los partidos con sus votantes. Legítimas debido a que logran "aceitar" los mecanismos intermediadores entre los políticos y sus seguidores, entre las instituciones públicas y los ciudadanos, entre lo nacional y lo local; además canalizan demandas de la población, erigiéndose como resolvedores reales o potenciales de problemas, fortaleciendo los lazos de confianza entre las partes.

Este tipo de construcción de liderazgos locales estuvo históricamente asociada al clientelismo político tanto en Uruguay como en el resto de Latinoamérica (Rama 1971; Bezzera Marcos, 1994; Cazorla, 1992). Bajo este concepto han sido analizadas distintas conformaciones sociales como el caciquismo mexicano, el coronelismo en Brasil, los punteros peronistas en Argentina, los caudillos políticos en Uruguay, entre otros, asociadas frecuentemente a la dominación y explotación entre dos actores jerárquicamente desiguales. Los estudios sobre el clientelismo político definen a las relaciones entre patrones y clientes como: particularistas, informales, asimétricas y recíprocas. $\mathrm{Si}$ bien estas características son adoptadas para definir algunas de las relaciones políticas informales entabladas por los referentes locales en su actividad como "mediadores", resulta necesaria una resignificación del propio concepto de clientelismo debido a que reduce este tipo de relaciones a un mero intercambio de favores por votos.

Esta clásica visión, permeada por las concepciones "utilitaristas" realiza un inevitable reduccionismo principalmente en dos sentidos: en 
primer lugar supone que los agentes se mueven solamente a través de razones concientes con el objetivo de conseguir el máximo beneficio con el menor coste y en segundo lugar, toda motivación pasa por un interés económico y su finalidad se encuentra en el beneficio material obtenido mediante el cálculo racional (Bourdieu 1997). Auyero sostiene que esta visión posee dos problemas centrales, a saber: el énfasis estratégico, que implica "reducir la dinámica del clientelismo a las acciones de individuos racionales y pragmáticos puede hacernos perder de vista los significados compartidos - aunque no cooperativamente construidos - que emergen y sostienen a esta acciones. Las lealtades, identidades grupales e identificaciones, esto es, la dimensión simbólica o cultural del clientelismo..." (Auyero 2001, 45). En segundo lugar la noción de utilidad, que posiciona al clientelismo como propiedades emergentes de elecciones pragmáticas y concientes de clientes, mediadores y patrones, siendo "el principio de estas decisiones y elecciones la maximización de utilidades" (ibid.).

Actualmente diversos autores formulan resignificaciones al concepto de "clientelismo político". Tanto Bobbio (1991) como O'Donnell (1996) proponen términos sustitutos al de clientelismo - "voto de intercambio" $\mathrm{y}$ "particularismo" respectivamente. Pese a esto, ambos continúan reduciendo un fenómeno complejo al intercambio instrumental en el período electoral. A diferencia de estos, Auyero (2001) propone el concepto de "mediación política"5 como un sustituto de "clientelismo" debido a que permite integrar al análisis diversas dimensiones de las relaciones políticas informales no contenidas en el concepto tradicional de clientelismo.

En relación a lo antes mencionado, a la hora de analizar las relaciones políticas informales en la izquierda uruguaya, proponemos sustituir el concepto "clientelismo político"-término al que además, parece imposible sacarle la carga peyorativa—por el de "mediación política". Es decir, una forma de articulación entre diversos actores políticos y sociales, comunitarios y partidarios, que implica el contacto inter-personal de dichos actores y al mismo tiempo una circulación real o potencial de recursos. Se pretende explorar como este tipo de prácticas son efectivas tanto para el éxito electoral en términos de obtención de votos como para la construcción de identificaciones políticas y sociales relativamente estables. 


\section{El proceso político nacional y su correlato en el departamento canario}

La denominada "partidocracia" del sistema político uruguayo ha estado sustentada por dos tempranos procesos en la historia política del país: la autonomización relativa del Estado y la consolidación de un elenco político estable y "profesional", generando de esta forma una progresiva monopolización por parte de los partidos políticos del rol intermediador entre el Estado y la Sociedad Civil. De acuerdo con Panizza, las características particulares del proceso de consolidación del Estado uruguayo hicieron que en su relacionamiento con la Sociedad Civil, esta no apareciera como una institución "autónoma" sino como un "centro institucional de alianzas y compromisos" sustentado por una multiplicidad de fracciones políticas. "Los partidos tradicionales gobernaron en función de una extensa red de intereses y fidelidades establecidas a través de una compleja trama de relaciones de clientela" (Panizza 1990). Estos neomitos de la cultura política uruguaya (Bayce 1989) se encuentran sustentados en lo que Aguiar (1984) destaca como la preponderancia de los clivajes políticos sobre los sociales a la hora de la conformación de lealtades, adhesiones, identidades y expresiones ciudadanas. Es por esto que los mecanismos de relacionamiento informal como el clientelismo político han sido relacionados con prácticas políticas propias de los partidos tradicionales a lo largo de la historia política del país. ${ }^{6}$

Con el triunfo de la izquierda en las elecciones nacionales y en ocho departamentos en las posteriores instancias municipales, este tipo de prácticas han sido puestas en discusión tanto por la academia como por la opinión pública. ¿La mediación política particularista es una práctica exclusiva de los partidos tradicionales o remite a una práctica extendida en la sociedad uruguaya más allá de la adscripción partidaria? Magri y Guerrini destacan que luego de la reforma constitucional del 1996 que separó las elecciones nacionales de las municipales, el clientelismo ha tenido mayor influencia en el desarrollo de estas últimas. Guerrini sostiene que las elecciones municipales anteriores demostraron que “... las redes políticas locales en el interior siguen beneficiando a la mayor capacidad de proyectar liderazgos (...) Inclusive gestiones fracasadas o al menos sumamente cuestionadas, no implicaron cambios de partido..." (Guerrini 2000, 181). ${ }^{7}$ Magri incluso afirma que 
las posibilidades de que la fuerza política de izquierdo triunfe en las elecciones municipales se encuentran condicionadas a la capacidad de "...enraizarse en las sociedades locales tejiendo redes políticas de sustentación" (Magri 2000, 183). Resulta de interés por ende analizar como operan estos mecanismos particularistas en la campaña política del triunfal partido de izquierda uruguayo: Frente Amplio-Encuentro Progresista-Nueva Mayoría (FA-EP-NM). ${ }^{8}$

\section{Redes políticas de apoyos locales}

Los resultados electorales en el departamento de Canelones en mayo del 2005 despertaron algunas interrogantes en cuanto al comportamiento de los votantes a la hora de apoyar a una lista, fracción o candidato en las urnas, que se encuentra en estrecha relación con las temáticas planteadas. ¿Por qué el rendimiento electoral de las diferentes facciones del FA-EP-NM es tan dispar a lo largo de todo el departamento? ¿Cómo puede ser que una lista creada para esta instancia, es decir con tan solo unos meses de antigüedad, reúna la mayor cantidad de votos de la fuerza política en cuestión en una de las localidades? ¿Cuál es el fenómeno por el cual en una localidad un sector obtenga una excelente votación y a seis kilómetros de distancia descienda estrepitosamente su electorado? A través del análisis de dos ejemplo concretos, el de la lista 8703 de la ciudad de Santa Lucía y la estrategia electoral implementada por el "Espacio de Democracia Avanzada"-Partido Comunista-, pretendemos generar un insumo para la reflexión de comportamientos electorales mediados por formas de cooptación del voto y de generación de adhesiones del tipo "cara a cara" o particularista. ${ }^{9}$

Para analizar estos dos ejemplos abordaremos la influencia de la construcción de apoyos locales y el rol crucial de los mediadores de acuerdo a conceptos del análisis de redes sociales. El término "red" gráfica tanto visual como conceptualmente los diferentes vínculos entre los individuos que la componen, es decir, múltiples vínculos horizontales y asimétricos de diversa índole. Las "redes sociales" se definen como: "Conjunto limitado de contactos directos e indirectos de una persona que se caracteriza por estar fundado en relaciones de carácter personal. De este modo, las redes incluyen a aquellas personas que están vinculadas por relaciones de parentesco, amistad, patronazgo, alianzas políticas y conocimiento" (Bezerra 1994, 4). 
En la literatura sobre redes sociales existen fundamentalmente dos criterios para delimitar este "conjunto de contactos directos e indirectos" a analizar. La demarcación clara y concreta de todos los participantes de la red excede las posibilidades del presente trabajo, ya que se deberían establecer todos los mediadores y simpatizantes involucrados en el desarrollo de la misma. Las características de las redes estudiadas hicieron de esto una tarea inviable debido a la cantidad y diversidad de personas involucradas. Es por esto que se adoptó una combinación de los criterios denominados por la literatura como "realista" y "nominalista" (Rodríguez 1995; Hanneman 2001). El criterio realista implica adoptar el punto de vista de lo actores para delimitar la extensión de la red, mientras que la perspectiva nominalista conlleva a delimitar la extensión de la red a partir de un marco conceptual específico. ${ }^{10}$

Las redes sociales y políticas, incluso las clientelares, implican un patrón regularizado de interacciones que es conocido, practicado y aceptado por los actores. Utilizando el concepto de Schutz de "subuniversos de significado", Auyero (2001) describe como las redes clientelares generan "mundos de sentido común" particulares, es decir estas redes sociales, políticas, clientelares implican el manejo de códigos compartidos, un aprendizaje de ciertas normas y dinámicas de funcionamiento, en suma, las redes se transforman en un ámbito de socialización.

En instancias políticas formales como son las elecciones, cobran importancia mecanismos de vinculación política informal, como los que sustentan a las redes políticas de apoyos locales, en las que, entre los múltiples lazos que unen a los involucrados encontramos a los clientelares. Las redes clientelares se encuentran entrelazadas con las redes sociales y políticas, es decir estas últimas otorgan el marco para el desarrollo de vínculos clientelares. Llegado a este punto resulta necesario plantear una definición propia de redes clientelares en consonancia con el concepto de mediación política: un conjunto de relaciones directas e indirectas construidas de forma interpersonal, regidas por pautas y normas informales, donde los vínculos entablados se caracterizan por ser particulares, asimétricos y recíprocos, conjuntamente con la existencia de un intercambio de recursos o la expectativa de realización del mismo.

Para poder analizar estas vinculaciones interpersonales, es que la 
mirada se dirigió fundamentalmente a los referentes locales-mediadores - y a las relaciones establecidas tanto con los integrantes de la candidatura a la Intendencia departamental como con los simpatizantes. Los vínculos entre los articuladores locales de la red-referentes o mediadores - no se desarrollan todos de igual forma debido a las diversas conformaciones de los mismos, en donde inciden atributos personales de los participantes, los diversos recursos y demandas en juego, así como redes de parentesco, vecinazgo y amistad. No obstante, consideramos pertinente establecer lo que en la literatura de análisis de redes se denomina como "equivalentes estructurales", es decir distintos individuos que poseen pautas relacionales similares con los otros actores del sistema. Este elemento se presenta como vital para comprender el funcionamiento de las redes, ya que individuos pertenecientes a diferentes sitios del departamento entablan con la población en general y con los simpatizantes en particular de cada localidad un relacionamiento directo, haciendo plausible la producción de confianza a través de la cercanía física y social, redundando en un incremento de sus bases sociales. De esta manera los mediadores locales son puntos de referencia en el funcionamiento de la red no solo como vehiculizadores de demandas y distribuidores de recursos, sino que además, ofician como referentes sociales y políticos en sus localidades, se encuentran en una posición que es reconocida por todos: se sabe donde viven, de que trabajan, su historia personal y sus vinculaciones. En suma, los mediadores se convierten en "referentes locales".

Estas múltiples vinculaciones de individuos que se dinamizan en la campaña electoral pero que en gran mayoría preexisten a la misma, se pueden asociar a lo que la literatura sobre redes sociales denomina "bloques", es decir, un grupo de individuos estructuralmente equivalentes que entablan relaciones de similares características con otros actores de la red. Los ejemplos que mencionaremos a continuación aportan un elemento adicional a esta definición: las relaciones que se observan en las redes en torno a la candidatura se encuentran geo-referenciadas, es decir, estos "bloques" se desarrollan en espacios geográficos específicos donde los referentes locales centran su actividad laboral, política y social. El concepto de "bloque" permite analizar el comportamiento electoral desde otra perspectiva, ya que posibilita comprender la conformación de "colchones electorales" de los referentes locales en sus espacios geográficos y sociales de referencia. 


\section{Una lista de sustento local: 8703}

La 8703 es una lista departamental que se construyó para las elecciones municipales del 2005. Su principal figura, Marcos Márquez, había sido electo edil departamental en anteriores instancias electorales bajo otros sub-lemas pertenecientes a la fuerza política en cuestión. En este caso, se buscó explícitamente instrumentar la lista a partir de referentes locales que pudieran reconvertir sus vínculos sociales locales en bases electorales. Si consideramos que la 8703 es una lista nueva, que se instrumentó a las apuradas, que no tiene una orientación ideológica específica, que no la apoya ni integra ninguna de las figuras nacionales del FA-EP-NM, podemos afirmar que la estrategia electoral fue un éxito. Si bien a nivel departamental fue la novena lista más votada dentro del FA-EP-NM obteniendo el 3\% de electorado de esta fuerza de izquierda, lo interesante es analizar comparativamente donde Márquez conformó su "bloque" en relación a otras zonas del departamento.

Generalmente las listas más votadas a nivel nacional y/o departamental mantienen una tendencia similar en las distintas localidades. El caso de la 8703 resulta paradigmático debido a que irrumpe en el electorado de su zona de influencia, colocándose como la lista más votada en la localidad de origen, rompiendo con la tendencia general de las listas del FA-EP-NM en el departamento.

\section{Cuadro 1.}

Votos y electorado de las nueve listas más votadas del FA-EP-NM

\begin{tabular}{|c|c|c|c|c|c|c|c|c|c|}
\hline & 609 & 90 & 738 & 2121 & 99000 & 77 & 1001 & 1738 & 8703 \\
\hline $\begin{array}{l}\text { Total de } \\
\text { votos en } \\
\text { Canelones }\end{array}$ & 40366 & 22846 & 18693 & 17395 & 15896 & 15020 & 8578 & 5881 & 5420 \\
\hline $\begin{array}{l}\% \text { de votos } \\
\text { dentro de } \\
\text { FA-EP-NM }\end{array}$ & 22.0 & 12.6 & 10.3 & 9.6 & 8.8 & 8.3 & 4.7 & 3.3 & 3.0 \\
\hline $\begin{array}{l}\% \text { de votos } \\
\text { en el } \\
\text { electorado } \\
\text { total }\end{array}$ & 14.4 & 8.2 & 6.7 & 6.2 & 5.7 & 5.4 & 3.0 & 2.1 & 1.9 \\
\hline
\end{tabular}

Dansilio-Duarte con datos cedidos por Abel Oroño. 
Comparando la distribución porcentual de los votos obtenidos por la 8703 a lo largo del departamento y en la ciudad de Santa Lucía respecto a las listas más votadas del FA-EP-NM (cuadro 1 y 2), en el único lugar que adquiere relevancia a nivel electoral es donde Márquez ha conformado personalmente su "bloque" en la red. El 33\% de los votos obtenidos por la lista 8703 se encuentran en la ciudad de Santa Lucía donde Márquez desarrolla prácticamente la totalidad de su actividad laboral, social y política. Esto adquiere aún más relevancia si consideramos que el padrón electoral de Santa Lucía tiene registrados 11,682 votos válidos, en un padrón departamental de 279,962 votos válidos. En suma, la lista 8703 concentra un tercio de sus votos en una localidad que representa poco más del $4 \%$ del padrón electoral del departamento.

\section{Cuadro 2.}

Comportamiento electoral en Santa Lucía de las nueve listas más votadas del FA-EP-NM

\begin{tabular}{lccccccccc}
\hline \hline & $\mathbf{8 7 0 3}$ & $\mathbf{6 0 9}$ & $\mathbf{1 0 0 1}$ & $\mathbf{7 3 8}$ & $\mathbf{1 7 3 8}$ & $\mathbf{2 1 2 1}$ & $\mathbf{9 0}$ & $\mathbf{9 9 0 0 0}$ & $\mathbf{7 7}$ \\
\hline $\begin{array}{l}\text { Total de } \\
\text { votos en }\end{array}$ & 1762 & 1338 & 931 & 686 & 592 & 549 & 487 & 380 & 342 \\
$\begin{array}{c}\text { Santa Lucia } \\
\% \text { de votos } \\
\text { dentro del }\end{array}$ & 22 & 16.6 & 11.5 & 8.5 & 7.3 & 7 & 6 & 4.7 & 4.2 \\
$\begin{array}{l}\text { FA-EP-NM } \\
\text { en Sta. Lucia }\end{array}$ & & & & & & & & & \\
$\begin{array}{c}\% \text { de votos } \\
\text { total en el } \\
\text { electorado } \\
\text { de Sta. Lucia }\end{array}$ & 15.1 & 11.5 & 8 & 6 & 5 & 4.7 & 4.2 & 3.3 & 3 \\
\hline
\end{tabular}

Dansilio-Duarte con datos cedidos por Abel Oroño.

Este caso es un claro ejemplo para comprender el funcionamiento de las redes construidas mediante relaciones interpersonales de interconocimiento. Es pertinente destacar que las únicas actividades de campaña electoral realizada por la lista 8703 con miras a elecciones municipales fueron: el reparto de listas en algunas localidades, "barriadas", ${ }^{11}$ conjuntamente y en el caso particular de Marcos Márquez ser uno de los coordinadores e intermediarios personales entre el 
candidato a la Intendencia y la población de Santa Lucía. La única publicidad en la prensa era local y se efectuaba mediante entrevistas, ya que la ausencia de propaganda explícita era prácticamente total. En este escenario la generación de adhesiones sociales a partir de una vinculación directa con la población de la localidad — conformando lo que denominamos como bloques-y su reconversión en bases electorales adquieren aún mayor relevancia para explicar el comportamiento electoral de esta ciudad. En estas instancias, la decisión electoral individual se encuentra supeditada en gran medida a la lógica y el entramado de significados propios de la redes.

\section{La exitosa estrategia electoral de Democracia Avanzada-Partido Comunista}

La estrategia electoral de Democracia Avanzada-Partido Comunista también tuvo como eje central a los referentes locales y la construcción de redes políticas de apoyo en torno a ellos. Se buscó obtener el mayor rédito de las individualidades locales que posee dicho sector, a partir de la división de la lista de votación en cuatro sub-listas geo-referenciadas, colocando a los referentes locales como cabeza de cada sub-lista. De acuerdo a lo declarado en las entrevistas con integrantes de este sector, se pretendió generar adhesiones mediante el fuerte vínculo social de los referentes en sus respectivas localidades: a sabiendas que en un contexto donde la política se observa como una actividad "lejana", se pretendió "acercarla" al votante mediante la asociación de la lista con personas de reconocida militancia y con amplia trayectoria social en cada localidad.

A partir de la lista de votación original-1001-se crearon tres listas más—2001, 31001 y 61001 — colocando al frente de las mismas a referentes locales. Obtuvieron una votación que algunos de lo referentes que entrevistamos a posteriori de las elecciones la destacaban como "un éxito", ya que si se suman los votos de las cuatro listas-1001, 2001,31001 y la 61001 -, estos llegan 16082, lo que los posiciona como la quinta fuerza política del Frente Amplio en Canelones-teniendo en cuenta que en la elección anterior había obtenido un magro resultado que no figuraba en el recuento de las listas más votadas.

Si observamos la distribución de la votación de cada una de las listas que componen el espacio Democracia Avanzada se presenta cla- 
ramente la delimitación geográfica de los resultados de cada una de las listas. Si observamos los cuadros 3 y 4 vemos una alta concentración de votos de las sub-listas en las zonas de influencia obteniendo una casi nula votación en otras zonas.

\section{Cuadro 3.}

\section{Zonas de influencia y porcentaje de votos de las listas de Democracia Avanzada}

\begin{tabular}{lcccc}
\hline \hline & 1001 & 2001 & 31001 & 61001 \\
\hline $\begin{array}{l}\text { Zonas de } \\
\text { influencia } \\
\text { de la lista. }\end{array}$ & $\begin{array}{c}\text { La Paz, Las } \\
\text { Piedras, Progreso, } \\
\text { Canelones } \\
\text { Santa Lucía, } \\
\text { y zonas aledañas }\end{array}$ & $\begin{array}{c}\text { Pando } \\
\text { Barros } \\
\text { Blancos } \\
\begin{array}{l}\text { en zona de votos } \\
\text { influencia }\end{array}\end{array}$ & $\begin{array}{c}\text { Cuidad de } \\
\text { la Costa }\end{array}$ & $\begin{array}{c}\text { Santoral, } \\
\text { Sauce, }\end{array}$ \\
\hline
\end{tabular}

Dansilio-Duarte con datos cedidos por Abel Oroño.

\section{Cuadro 4.}

Porcentaje de votos de cada lista en la zona de influencia de las otras

\begin{tabular}{lcccc}
\hline \hline Listas & 1001 & 2001 & 31001 & 61001 \\
\hline 1001 & 79.7 & 0.3 & 0.6 & 1.4 \\
2001 & 8.4 & 95.8 & 2 & 0.8 \\
31001 & 6.5 & 2 & 95.8 & 0.5 \\
61001 & 4.8 & 1.6 & 0.3 & 96.7 \\
\hline
\end{tabular}

Dansilio-Duarte con datos cedidos por Abel Oroño.

Mientras que la 61001 concentra el $96.7 \%$ de sus votos en la zona del Santoral, Sauce, Suárez y Toledo, obtiene 23 votos en la zona de influencia de la 1001, 13 en la región de la 2001 y 1 sufragio en el territorio de la 31001, comportamiento que se repite en cada una de las restantes sub-listas. Nuevamente vemos reflejado en el éxito electoral la influencia de los referentes locales y las redes locales de apoyos. Mediante el caso concreto de la 61001 intentaremos explicar como operan este tipo de mecanismos. La sub-lista 61001 agrupa a 
militantes de localidades que se encuentran atravesadas por la ruta 6- de ahí el nombre de 61001-donde particularmente resalta uno de la ciudad de Sauce: Lorenzo. La 61001 concentra dentro de las ciudades de Sauce, Suárez y Toledo el $75 \%$ de los votos, territorio que justamente coincide con las zonas de referencia de nuestro referente local, vale la pena resaltar que la distancia que separa a las ciudades mencionadas es aproximadamente 6 kilómetros.

Actualmente la mayor parte de la actividad social de Lorenzo se desarrolla en Sauce, a través de su participación en el comité patriótico, actividades culturales de diversa índole y en la comisión del club de básquetbol de la localidad. La actividad política de Lorenzo en la zona y principalmente en campaña no respondió a los cánones más tradicionales de los caudillos en campaña política — exhibición pública, exposiciones orales grandilocuentes, exhibición junto a figuras de poder, etc. - sino que se focalizó en un tipo de actividades más informales y cotidianas, una forma menos explícita de hacer campaña. Nos encontramos entonces ante un candidato a edil, que encabeza la lista, con una campaña de "bajo perfil", que posee una gran inserción social - mediante su actividad social y laboral-y que la lista que encabeza se constituye en la tercera mas votada de Sauce.

Su relacionamiento con la ciudad de Toledo es principalmente por sus lazos familiares y por su actividad laboral, así como su vínculo con la ciudad de Suárez. En ambas localidades implementó la misma estrategia de hacer campaña con un "perfil bajo" pero apelando a todas las conexiones establecidas a lo largo de su vida en estas localidades. De esta manera se presenta como un factor clave para el análisis del comportamiento electoral el estudio de las redes sociales así como un insumo para observar la formación de elites partidarias. De acuerdo a lo observado consideramos que los sectores y partidos que logren conformar sus filas con personas de gran inserción social, a los cuales la comunidad recurre a ellos para la resolución de problemáticas de diversas índole, donde se establecen relaciones de reciprocidad entre los referentes y la población - canalizando recursos y demandas-, posiblemente se encuentren con escenarios electorales favorables.

Los ejemplos antes descriptos nos permiten observar en dos casos concretos la influencia de los referentes locales en la captación de adhesiones mediante el establecimiento de conexiones interpersonales, es decir mediante la formación de bloques o redes políticas geo-refe- 
renciadas. A partir del trabajo de campo realizado sostenemos que el FA-EP-NM posee escenarios electorales favorables debido a que han logrado construir "colchones" electorales locales a partir de la constitución de redes sustentadas en referentes locales de gran influencia para la comunidad. A través de las entrevistas a los simpatizantes y de lo expresado por los participantes de las actividades de campaña, el estilo de los caudillos políticos tradicionales-grandilocuentes y distantes-ha experimentado una suerte de deslegitimación en la población. Es pertinente destacar que lo que se encuentra deslegitimado en estos casos es el "estilo" del caudillo, es decir el formato en la presentación pública del candidato y los atributos que se exaltan del mismo, no la manera informal de relacionamiento político. Los referentes de izquierda retoman la práctica política informal, pero desde un formato diferente al viejo caudillo tradicional, estas personas presentan gran vinculación con la comunidad y una gran dedicación a la organización y participación en actividades locales así como una predisposición positiva a un intercambio denso con la comunidad, erigiéndose como bastiones electorales en las elecciones 2005 del FA-EP-NM.

\section{"No es lo que tu sabes sino a quién conoces": las ventajas del capital social ${ }^{12}$}

Llegado a este punto es necesario analizar el fenómeno desde otra perspectiva, es decir observar el rol que juegan los mediadores en las respectivas localidades, los atributos que los erigen como tales y los mecanismos de relacionamientos con sus votantes. ¿Qué atributos posee un referente local que lo diferencia de otros actores políticos? ¿Cómo se relaciona con su comunidad? ¿Cómo canalizan recursos públicos sin entrar en contradicción con los marcos democráticos?

Los referentes locales se encuentran conectados más allá de las fronteras de la localidad: poseen conexiones "hacia dentro" y "hacia fuera" de la misma, como sostiene Auyero "El concepto de mediador se refiere al status que funciona como un lazo entre el sistema local y el sistema nacional. (...) Los mediadores 'están aquí' y 'están allí'; tienen casi similares pertenencias de clase social con sus clientes. Lo distintivo en los mediadores es la cantidad acumulada de capital social" (Auyero 2001, 105). Bourdieu define capital social como "el conjunto de recursos actuales o potenciales que se encuentran ligados 
a la posesión de una red durable de relaciones mas o menos institucionalizada de inter-reconocimiento" (en Grill 1999, 42). Lin (2001) se refiere al capital social como el capital "capturado" a través de las relaciones sociales, en este sentido el capital social es visto como una "ventaja social" - virtud de los actores - en cuanto a conexiones $\mathrm{y}$ acceso a recursos dentro de la red o grupo al que se pertenezca. El capital social acumulado por un individuo se vuelve un recurso en sí mismo; recurso generado mediante mecanismos informales y bajo éstos parámetros es utilizado para un objetivo político como son las elecciones. Esta suerte de "ventaja social" es uno de los elementos que permite diferenciar a los referentes locales tanto de los simpatizantes como del equipo del candidato.

Las conexiones directas e indirectas de pertenecer a una red o a la superposición de múltiples redes, viabiliza que los individuos se encuentren vinculados a círculos extensos, lo que redunda en reiteradas ocasiones en la resolución efectiva o potencial de problemas. Retomando a Lin, "estableciendo conexiones directas e indirectas es que se puede facilitar el acceso a recursos. A través de lazos directos e indirectos, el capital social de un actor se expande por encontrarse inmerso en una red social. Debido a esto, el capital social es contingente a los recursos inmersos en los lazos directos e indirectos y accesibles a través de estos mismos" (Lin 2001, 44). ${ }^{13}$

El capital social generado por los referentes hace plausible que estos se vuelvan personas preciadas tanto para la comunidad-por su acceso a recursos escasos y conexiones por fuera de la comunidad misma - y para la candidatura - debido a que representan un vínculo de acceso a potenciales votantes y una suerte de canal de comunicación entre estos y el candidato. Analizaremos al capital social como un "instrumento" de los referentes locales que posibilita la reducción de distancias entre simpatizantes y la candidatura, redundando en la resolución de problemáticas en su comunidad al mismo tiempo que genera adhesiones político partidarias. Lin (2001) menciona cuatro elementos que hacen del capital social un "instrumento":

1. Facilita el flujo de información entre las diferentes partes que conecta.

2. Las conexiones sociales generan influencia en aquellos individuos que desempeñan roles "críticos" en la toma de decisiones que involucran a más actores. 
3. Las conexiones sociales y el reconocido relacionamiento del individuo es concebido como una "credencial social" que refleja el acceso a redes y relaciones sociales.

4. El capital social refuerza la identidad y el reconocimiento mutuo entre los involucrados en las relaciones.

Por último, los posibles recursos a los que se accede por medio del capital social pueden ser tanto materiales como simbólicos. Las personas o los grupos depositan en ellos sentidos y significados diversos, por lo tanto el valor asignado a los recursos se encuentra signado por la historia, el lugar y las experiencias colectivas de cada grupo. Lin sostiene que "El acceso y el uso de estos recursos es temporal y prestado en el sentido de que estos actores no los poseen efectivamente. (...) Una de las implicaciones del uso del capital social es asumir la obligación de reciprocidad o compensación" (Lin 2001, 56) ${ }^{14}$ Esta idea nos abre una nueva dimensión: el estar ligado o conectado y usufructuar de recursos derivados de esa conexión genera una obligación de la reciprocidad o compensación.

Si bien el capital social es crucial para entender el papel de los referentes y el acceso potencial que generan estas conexiones hacia "afuera" y hacia "adentro", conjuntamente con la construcción y fortalecimiento de identidades compartidas y vínculos afectivos, es necesario analizar como experimentan los integrantes de la red el intercambio de recursos que supone la reciprocidad de dicha relación y que consecuencias trae para estos actores.

\section{La performance del mediador: el intercambio como un acto de solidaridad}

El intercambio en reiteradas ocasiones se vuelve difuso a los ojos del observador externo, a causa de que éste no se percibe como tal, en otras palabras, los individuos que solucionan un problema o realizan un favor no lo conceptualizan como una cuestión puramente estratégica pensando en que en el futuro ese favor se convertirá en un voto o algún otro beneficio de interés. Cuando se realiza una acción de este tipo se vivencia en este caso como "desinteresada", por fines altruistas o por creencias ideológicas.

Por lo general en los ámbitos como los observados lo que se da o se hace por el otro es visto como un "obsequio", algo que no genera 
una obligación de devolución. Ahora bien, retomando a Lin (2001) y a Bourdieu (1997), en estas relaciones el obsequio gratuito no existe, sino que obedece a la lógica de la reciprocidad. ¿Por qué pensamos que se puede hablar de intercambio? Hay tres elementos que aparecen tanto en las observaciones como en las entrevistas que justifican esta idea: 1. hay demandas realizadas, 2 . hay recursos reales o potenciales con los que se pueden suplir y 3 . existe la expectativa de la reciprocidad en el favor.

Las demandas son de índole variada - tanto de bienes y servicios públicos como privados. No obstante y más allá de las características de las mismas, la canalización de estas se instrumenta en una práctica totalmente informal: los detentores de problemas no se dirigen en este caso a la Intendencia o a la Junta Local—los ámbitos formales estipulados para la recepción de algunas de las demandas recabas en el trabajo de campo - sino que, lejos de esto, recurren a la figura del referente local que ofrece un camino mas efectivo y pragmático para la resolución de problemas. $\mathrm{Al}$ mismo tiempo los referentes también son los encargados de canalizar o solucionar demandas de índole privada y particularistas como lo son: la asistencia médica gratuita, el reparto de medicamentos, la realización de trámites fuera de la localidad, acceso a fuentes laborales tanto en la esfera pública como en la privada, entre otras. Existen múltiples hipótesis sobre este tipo de intercambios y los motivos por los que se encuentran sustentados. Tanto Boissevain (1986) (ver bibliografía) como Adler de Lomnitz (1994) señalan que las redes informales de intercambio se desarrollan al interior de los sistemas formales supliendo sus deficiencias, pero no se limitan a explicar estos sistemas como consecuencia de la escasez de recursos, ambos coinciden en que los vínculos de reciprocidad que permiten el intercambio están anclados en lealtades sociales primarias como el parentesco o la amistad o secundarias como el compañerismo o la pertenencia a grupos sociales.

Ahora bien, cabe preguntarse ¿cuál es la acción preestablecida en el intercambio para que dentro del sub-universo de significados propio de la mediación política, este sea concebido como "un acto de solidaridad"? Auyero (2001) partiendo de la premisa de que los intercambios son experiencias humanas vividas, sostiene que el conjunto de creencias, presuposiciones, repertorios y hábitos que acompañan a los mismos poseen la misma relevancia que los propios intercam- 
bios. Para no caer en el argumento mecanicista de considerar a los mediadores y a los simpatizantes como agentes pavlovianos - votan, concurren a actos y manifiestan públicamente su apoyo en respuesta a estímulos materiales, favores, bienes o gratificaciones simbólicas-se debe explorar concretamente el sistema de representaciones adheridos a los intercambios, la performance que públicamente presenta a la distribución de recursos particularista, no como producto de un intercambio recíproco y asimétrico sino como actos de solidaridad mutua. Para esto consideramos pertinente analizar como los mediadores "se erigen a si mismos como sinónimos de las cosas y sinónimos de la gente" (Gay 1997, 183) vinculándose personalmente e implícitamente con la distribución de favores y recursos o con los logros de políticas sociales específicas, ya que, esto es un elemento central en la presentación pública de los "actos de solidaridad mutua".

A través de un ejemplo concreto recabado del trabajo de campo expondremos tres aspectos centrales de la performance de un referente local y la presentación pública del mismo en la distribución de recursos como "actos solidarios", cruciales a la hora de comprender la construcción de significados compartidos por los participantes de la red de relaciones interpersonales.

\section{Personalización de logros no personales: ubicación del mediador en la red}

La obtención de logros colectivos así como políticas exitosas implementadas desde las distintas esferas estatales son plausibles de ser "adueñadas" y personalizadas en nombre de algún actor en especial y en este caso en particular por los referentes locales. Yolanda - referente local de una ciudad de 15 mil habitantes - manifiesta haber participado en todos los últimos logros que se han conseguido en Santa Lucía, desde la instrumentación —obtención de recursos y organización — de un comedor que atiende a más de 300 personas hasta la organización y la atención en los centros descentralizados de salud, etc. En este punto no es importante el grado o no de influencia en la implementación y desarrollo de estas políticas, lo que nos importa visualizar es: como públicamente se presenta como participe y gestora de logros que implican más actores que ella y al colectivo al cual se refiere, sus compañeros de militancia del comité de base. ${ }^{15}$ 
El recurso retórico utilizado en sus declaraciones permite visualizar como logros tanto personales como del comité que preside, objetivos $\mathrm{y}$ proyectos que por lo menos exceden ampliamente las funciones y recursos de un comité de base y del referente. De esta forma magnifica su rol y lo expande simbólicamente mas allá de los recursos que efectivamente posee y canaliza, exaltando sus atributos personales, permitiendo ser concebida dentro de la red como una desinteresada "resolvedora de problemas", lo que le confiere un reconocimiento social tanto a su actuación como a su solidaridad.

\section{Manipulación de la identidad: yo soy como vos pero no lo soy}

En un capítulo de la serie Los Simpsons, Homero-el padre de familia - consigue un nuevo trabajo en otra ciudad. En la primera interacción con su nuevo jefe este le dice: "Homero, yo no soy tu jefe, estamos trabajando ambos con el mismo objetivo, no me veas como tu superior sino como un igual, aunque tenga un cargo mas importante que el tuyo, tenga un mejor salario, vacaciones mas largas y estos mocasines mas lindos que los tuyos...". El recurso retórico utilizado por Hank Scorpio - el nuevo jefe de Homero-en la dualidad de su presentación es el mismo que implementan los referentes locales, donde Yolanda no es la excepción. Por una parte afirma vehementemente su pertenencia a los órganos "populares" de participación, "Yo siempre digo que yo soy base, base de comité de base" "siempre digo que yo soy base, que yo soy pueblo y como pueblo me expreso". Al mismo tiempo el "ser base" queda subsumido en un colectivo mas amplio como lo es "ser pueblo". De esta forma la mediadora en cuestión se presenta como una más, inserta en "el pueblo" desde un órgano "de base" donde construye y fortalece el imaginario de igualdad entre pares, diluyendo el "yo" en un colectivo, es decir, disolviendo las distancias existentes en la red entre el "resolvedor de problemas" y los "detentadores de problemas", entre referentes y simpatizantes. Bajo el entramado de significados propio de las redes, términos como "compañero" adquieren especial relevancia ya que permite percibir como iguales individuos que ocupan roles diferentes, haciendo plausible uno de los aspectos de la presentación pública de nuestro mediador: somos "base", somos todos "pueblo," somos todos "compañeros", somos todos iguales. 
El barrio donde vive es uno de los más carenciados de la ciudad, donde predominan las paredes de chapas y bloques sin revestir, a diferencia de la casa de nuestra referente que destaca por su color amarillo, su techo de tejas, aberturas en madera, garaje, etc. La casa de la mediadora, conjuntamente con establecer una diferenciación económica con su entorno próximo delimita una distinción simbólica. $\mathrm{Al}$ mismo tiempo, tanto en las observaciones como en la entrevista realizada, nuestra mediadora hace referencia de forma casi permanente a su cercanía con los círculos políticos locales como departamentales. En la "barriada" realizada cerca de su hogar, Yolanda es la encargada de introducir al candidato en su presentación pública, presentándolo a los "vecinos" que se acercan - a los cuáles conoce por nombre y apellido y viceversa-, golpeando las puertas de las diferentes casas para que sus moradores saluden al "futuro intendente". La referente cumple con una de la funciones de su rol de mediación, reducir distancias entre los participantes de la red, así como presentarse públicamente como cercana a la figura de poder.

De esta forma nuestra mediadora se define como "pueblo", como una "compañera" mas en relación al resto, al mismo tiempo que se define como diferente del resto a partir de la relevancia social de su accionar y su cercanía con distintos círculos de poder. De esta forma se erige dentro del entramado de significados propio de las redes como una "resolvedora de problemas", al mismo tiempo que su vehemente afirmación de ser simplemente una persona mas dentro del colectivo, posibilita dentro de la red, decodificar el intercambio asimétrico y recíproco como un favor entre pares, como un gesto de solidaridad entre iguales. De esta forma parafraseando a Hank Scorpio la presentación pública de nuestra mediadora se podría resumir de la siguiente manera: "yo soy una compañera mas, estamos trabajando ambos con el mismo objetivo, no me veas como tu superior yo soy pueblo igual que vos, aunque sea la presidenta del comité, mi esposo ocupe cargos de confianza del Intendente y tengamos una relación familiar con él, tenga acceso a recursos que otros no tienen y tenga una casa mas ostentosa que la tuya".

\section{Sacrificio sin rédito: la solidaridad solidaria}

El tercer y último aspecto a considerar en la presentación pública de Yolanda es su desinteresado trabajo por el bien público. Como 
referente local destaca, por un lado, su cantidad de actividades y su constante e incansable trabajo por la sociedad utilizando permanentemente como prefijo auto referencial: "mi tarea en la sociedad...", "nuestro trabajo en la zona". Similares afirmaciones realiza en relación a la permanente recurrencia a su persona por parte de la comunidad como una "revolvedora de problemas". Concibe su accionar como un "trabajo", destacando todas las acciones que realiza así como el tiempo y sacrifico que conllevan, en suma los recursos que ofrece para que circulen en la red. Sin embargo en ningún momento hace referencia ni mención al rédito que ella obtiene por su trabajo, al contrario se debe inferir de sus dichos y de su accionar relevado en las observación que todo su "sacrificio", "tiempo" y "trabajo" es una acción totalmente desinteresada guiada por un interés altruista. De esta forma nuestra mediadora integra en su presentación pública su accionar como un acto de solidaridad, ya que todo su trabajo, sacrificio y tiempo solo tiene por objetivo la distribución de recursos de forma altruista.

De esta forma observamos como el mediador en su presentación pública tiene una pauta de acción preestablecida que hace plausible para los integrantes de la red decodificar el intercambio y la distribución informal y personalizada de recursos como actos únicos de solidaridad entre pares. Los puntos anteriores permiten observar dos aspectos fundamentales para la sustentación de las relaciones particulares entre los miembros de la red. Por un lado, entender el doble juego del broker, es decir su presentación pública como "igual" al mismo tiempo que evidencia su "poder posicional", resulta útil para entender como estos se erigen como articuladores óptimos de las redes construidas en torno a la candidatura. Por otro lado, el rol que desempeñan implica una actualización de los lazos ente los miembros de la red y el fortalecimiento de sub-universos de significados, vital para el funcionamiento y la perdurabilidad de la misma.

\section{Conclusiones}

En las contiendas electorales estudiadas se constata una exaltación de las figuras políticas locales, así como estrategias electorales que hacen énfasis en las relaciones "cara a cara" entre las figuras políticas - tanto departamentales como locales-y sus simpatizantes. El contexto local—representado por la ciudad, sus aledaños y la serie 
vínculos cotidianos y asiduos que estos espacios conllevan - poseen gran influencia para la creación de adhesiones y lealtades políticas y apoyos electorales. Una suerte de "localismos" que plataforma figuras locales con gran éxito electoral.

Declaradamente los apoyos y las adhesiones estuvieron sustentadas en relaciones interpersonales, que implicaban vinculaciones entre los simpatizantes y los referentes locales - sean estos candidatos o no-que excedían la política partidaria propiamente dicha. El doble rol de los referentes hace plausible catalogarlos como mediadores políticos, ya que, articulan las diversas redes tejidas en torno al candidato, reduciendo las distancias - materiales y simbólicos-entre la Política y la Sociedad Civil, entre los candidatos y simpatizantes, entre Marcos y las Marías y los Juanes. Las relaciones "cara a cara", constituyen redes de relaciones en torno a la candidatura, cruciales a la hora de construir figuras políticas locales y de un posterior éxito en las urnas locales. La izquierda uruguaya a adoptado este mecanismo de relacionamiento político informal, resignificándolo: sostenemos entonces que el relacionamiento "cara a cara" constituye una forma de "hacer política" y de generar adhesiones y apoyos de creciente influencia tanto en las campañas electorales como en la gobernabilidad de los municipios.

Los fenómenos políticos analizados en el presente artículo no son características exclusivas del proceso democrático uruguayo, lejos de esto, abunda en la literatura estudios sobre estos fenómenos en diversos países latinoamericanos. Existe, en general, una noción relativamente extendida de una suerte de "convivencia y entrecruzamiento" en las democracias latinoamericanas de instituciones formales - como son las elecciones - con instituciones de carácter informal - como lo son las redes de relaciones interpersonales de carácter particularista que sustentan figuras políticas locales como las estudiadas. Múltiples estudios latinoamericanos tratan la temática desde una óptica que se busco recuperar en este trabajo y que dan cuenta de lo extensivo del fenómeno en la región. Auyero (2001) en su libro "La política de los pobres. Las prácticas clientelistas del peronismo" se dedicó a estudiar las redes políticas informales entre los punteros peronistas y sus seguidores en las "villas miserias" argentinas, vinculando tanto necesidades materiales como simbólicas en la construcción de dichas redes clientelares, posicionándolas, no como un mal que es necesario 
erradicar para el desarrollo de una democracia plena, sino como una estrategia de supervivencia legítima en este contexto particular. Por otro lado, Grill (1999), se dedica a estudiar en Brasil la campaña política de dos candidatos y de sus colaboradores o "grandes electores"-una suerte de correlato de nuestros referentes locales-, en las diversas localidades, observando como la construcción de apoyos políticos se encuentra sustentada en identificaciones sociales y geográficas entre los seguidores y los articuladores locales de la candidatura. Un tercer ejemplo de los estudios latinoamericanos sobre la temática, lo constituye Adler de Lomnitz (1994), en una serie de artículos donde explora la "reciprocidad de favores" entre políticos y seguidores en diversos contextos sociales y culturales como en la clase media chilena y en una barriada de la ciudad de México.

Mas allá de los matices conceptuales, así como los diferentes contextos donde se desarrollan los trabajos empíricos, surgen varios elementos comunes, entre los que destaca la mirada a la fortaleza de las lealtades primarias - cimentadas en una relacionamiento personal, donde la cercanía física y simbólica posibilita el establecimiento de relaciones basadas en la confianza - en el establecimiento de adhesiones político partidarias. Esto genera sistemas informales de intercambio y reciprocidad, redundando en el fortalecimiento de un sistema de mediación política que se torna clave para la comprensión de la construcción de apoyos electorales y lealtades políticas en Latinoamérica.

Frente a un generalizado desencanto de la ciudadanía con los proyectos políticos nacionales en los gobiernos latinoamericanos, se presenta como un aspecto clave el rol de los referentes locales como interlocutores válidos entre la localidad y las instituciones políticas formales, entre lo cercano y cotidiano con los distante y burocrático. Al decir de un simpatizante de la ciudad de Santa Lucía "si no podemos arreglar el mundo, por lo menos vamos a arreglar la manzana". Los referentes locales a su vez presentan características novedosas a las que presentaban los antiguos caudillos políticos, características que los posicionan incluso como promotores particularistas de las ventajas democráticas. Si bien ambos generalmente no poseen recursos materiales propios que puedan distribuir, sino que a través del capital social generado y de las conexiones entabladas hacia fuera y hacia dentro de la localidad vehiculizan el acceso a recursos estatales a sus 
habitantes. Los referentes locales poseen una "performance" que los erige ante sus simpatizantes como iguales, presentando sus logros como "actos de solidaridad mutua", en pro del bien colectivo. Reducen las distancias existentes y personalizan vínculos, hasta ahora lejanos y distantes.

Estas formas particularistas de interacción política, que se encuentran extendidas en diversos contextos latinoamericanos no implican una contradicción con las normas democráticas, ni tampoco son resabios de formas atrasadas en un continente en proceso de modernización. Son formas híbridas, viables y legítimas de relacionamiento político.

\section{Notas}

1 Luego de la reforma constitucional del 1996 el sistema electoral ha quedado dividido de la siguiente forma: en una primera instancia elecciones partidarias internas, una segunda instancia elecciones nacionales del Poder Ejecutivo y Legislativo y por último elecciones del Ejecutivo y Legislativo departamental.

2 Canelones es el departamento de Uruguay de mayor población luego de Montevideo. Posee un bagaje político tradicional, donde prácticamente la totalidad de las elecciones hasta la actualidad las ganó un solo partido: el Partido Colorado. En las elecciones municipales estudiadas en el año 2005 el Frente Amplio-Encuentro Progresista-Nueva Mayoría obtuvo el 64\% de los votos en todo el departamento.

3 El análisis del clientelismo bajo la óptica dicotómica referida conlleva una lectura ahistórica, dado que no considera los diferentes contextos y particularidades sociales, políticas, económicas, culturales, etc. en los que se desarrollan estos procesos.

4 “... existen buenas razones para creer que esté disminuyendo el voto de opinión y esté aumentando el voto de intercambio, (...) el voto dirigido hacia los output, (...) basado frecuentemente en la ilusión del do ut des (apoyo político a cambio de favores personales)" (Bobbio 1991, 25).

5 “... un registro detallado de las maneras en que alguna gente resuelve sus necesidades diarias de sobrevivencia a través de la mediación política (mi sustituto para "clientelismo político") le proveerá de un modo de ver el enraizamiento de la cultura política en las redes de resolución de problemas" (Auyero 2001, 41).

6 El sistema de partidos uruguayo en la actualidad se encuentra conformado por cuatro partidos: el Partido Colorado, el Partido Nacional-históricos partidos tradicionales-, el Frente Amplio-Encuentro Progresista-Nueva 
Mayoría - conglomerado de agrupaciones de izquierda-y el Nuevo Espacio-partido minoritario.

7 Desde 1996 las elecciones nacionales-donde se eligen el presidente y el vice-presidente y los integrantes del Poder Lesgislativo, senadores y diputados-se encuentran separadas de las elecciones municipales-donde se eligen los Intendentes de los 19 Departamentos y los ediles departamentales.

8 De aquí en adelante utilizaremos la sigla FA-EP-NM para denominar a la fuerza política de izquierda uruguaya.

9 El FA-EP-NM se encuentra conformada por múltiples agrupaciones de izquierda que se han ido anexando a lo largo de los años y que en las elecciones tanto nacional como municipales presentan listas propias unificadas en torno a la figura del/los candidatos.

10 En una primera instancia del trabajo de campo delimitamos la red a partir de entrevistas o diálogos informales con informantes calificados en las primeras observaciones de campo. Esto posibilitó comenzar a identificar a los distintos individuos en sus respectivos roles, lo que denominamos como el "mapeo de la red". Para trazar el mapeo de la red nos apoyamos fundamentalmente en diálogos informales con la comitiva al mismo tiempo que con sujetos que se destacaban por su cercanía con el candidato, en suma adoptamos el punto de vista de los actores inmersos en la red para ir delimitando a otros articuladores locales de la misma. Paralelamente a este proceso fuimos definiendo teóricamente los roles que relevábamos en las observación de campo, de esta forma los conceptos de patrón-broker-cliente propuestos por la literatura sobre el tema, tienen un correlato empírico definido como candidato-referentes locales-simpatizantes.

11 Las "barriadas" fueron la actividad proselitista por excelencia, esta actividad consiste en recorrer junto a las figuras de poder las distintas zonas de cada una de las localidades para dialogar "cara a cara" con los pobladores. Los referentes locales organizan el recorrido e introducen al candidato a intendente en cada dialogo, presentándolo y narrándole las problemáticas particulares de cada uno de sus vecinos.

12 "It's Not Just What You Know but Who You Know"-las comillas son del autor (Lin 2001, 41).

13 Traducción propia.

14 Traducción propia.

15 El comité de base es el órgano político y operativo del Frente Amplio en las distintas localidades o barrios. 
Dansilio y Duarte / Redes políticas informales en la izquierda uruguaya

\section{Obras citadas}

Adler de Lomnitz, Larissa. 1994. Redes sociales, cultura y poder: ensayos de antropología latinoamericana. México: FLACSO.

Aguiar, César. 1984. Elecciones y partidos. Revista Uruguay Hoy vol 4: Ciedur.

Auyero, Javier. 2001. La política de los pobres. Las prácticas clientelistas del peronismo. Cuadernos Argentinos. Buenos Aires: Manantial.

Bayce, Rafael. 1989. Cultura política uruguaya. Desde Batlle hasta 1988. Montevideo: Fundación de Cultura Universitaria.

Bezzera Marcos, O. 1994. Bases sociais da prática da corrupçào no Brasil. Brasilia: UNB.

Bobbio, Norberto. 1991. El futuro de la democracia. México: Fondo de Cultura Económica.

Boissevain, Jeremy. 1986. El patronazgo en Sicilia. En Patronos y clientes en las sociedades mediterráneas, editado por Ernest Gellner, 115-135. Madrid: Ediciones Júcar.

Bourdieu, Pierre. 1997. Razones prácticas. Sobre la teoría de la acción. Barcelona: Anagrama.

Cazorla, José. 1992. Del clientelismo tradicional al clientelismo de partido; evolución y características. Barcelona: Working papers, ICPS.

Escalante, Fernando. 1995. Clientelismo y ciudadanía en México. Análisis Político. 26 (sep-dic): 31-39.

Gay, Robert. 1997. Entre el clientelismo y el universalismo. Reflexiones sobre la política popular en el Brasil urbano. En Favores por votos, editado por Javier Auyero, 65-92. Buenos Aires: Losada.

Grill, Igor. 1999. As bases sociais dos compromissos: candidatos, recursos e configuracoes de apoios. Cuadernos de Ciencia Política 3. Porto Alegre: Universidad Federal de Río Grande do Sur.

Guerrini, Aldo. 2000. El peso politico de los intendentes del interior: apuntes para una discusión a la luz de las últimas consultas electorales. En Elecciones 1999/2000. Montevideo: ICP; Banda Oriental.

Günes-Ayata, Ayse. 1997. Clientelismo: premoderno, moderno, posmoderno. En Favores por votos, editado por Javier Auyero, 41-63. Buenos Aires: Losada.

Hanneman, R. Introducción a los métodos de análisis sociales. $<\mathrm{http} / / \mathrm{wizard}$. ucr.edu $>$.

Lin, Nan. 2001. Social capital. Cambridge: Cambridge University Press.

Magri, Altair. 2000. La llave del triunfo electoral en Mayo 2000: reelección, continuidady "por la vuelta". En Eleciones 1999/2000. Montevideo: ICP; Banda Oriental. 
O’Donnell, Guillermo. 1996. Otra institucionalización. La Política, n². Buenos Aires.

Panizza, Francisco. 1990. Uruguay: batllismo y después. Pacheco, militares y tupamaros en la crisis del Uruguay battlista. Montevideo: Ediciones de la Banda Oriental.

Rama, Germán. 1971. El club político. Montevideo: Arca Editorial.

Rodríguez, J. 1995. Análisis estructural y de redes. Madrid: CIS. 